\title{
Characterization of Intermediate Phases Formed Between Solid Nickel and Liquid Zinc During Use as an Encapsulated Phase Change Material in Solar Thermal Energy Storage Systems
}

\author{
J. C. Sabol • W. Z. Misiolek • A. Oztekin • \\ S. Neti
}

Received: 5 August 2012/Revised: 21 September 2012/Published online: 13 October 2012

(C) Springer Science+Business Media New York and ASM International 2012

\begin{abstract}
Of the new material systems under investigation for use in higher temperature phase change materialbased solar thermal energy storage (TES) systems, Zn encapsulated in $\mathrm{Ni}$ is proposed to increase storage capacity and efficiency by allowing solar TES systems to operate at higher temperatures. However, it is possible that the formation of intermediate phases could impede such storage. This study serves to characterize the intermediate phases formed between $\mathrm{Zn}$ and $\mathrm{Ni}$ at approximately $450{ }^{\circ} \mathrm{C}$ for various exposure times between 1 and $16 \mathrm{~h}$. Out of four possible intermediate phases present in the $\mathrm{Ni}-\mathrm{Zn}$ equilibrium phase diagram, only two were found to exist between $\mathrm{Ni}$ and $\mathrm{Zn}$ upon quenching under experimental conditions. The combined layer thicknesses for each specimen increased with increasing exposure time and ranged from 25 to $335 \mu \mathrm{m}$ in the specimens exposed 1 and $16 \mathrm{~h}$, respectively. Electron probe microanalysis showed that the compositions of each intermediate phase corresponded to the $\gamma$ and $\delta$ phases of the $\mathrm{Ni}-\mathrm{Zn}$ equilibrium phase diagram. Electron backscattered diffraction confirmed the presence of the $\gamma$ and $\delta$ phases and showed that their structures corresponded to the $\mathrm{NiZn}_{3}$ and $\mathrm{Ni}_{3} \mathrm{Zn}_{22}$ structures, respectively.
\end{abstract}

J. C. Sabol ( $(\varangle)$. W. Z. Misiolek · A. Oztekin · S. Neti Institute for Metal Forming, Lehigh University, Bethlehem, PA 18015, USA

e-mail: jcs209@lehigh.edu

J. C. Sabol · W. Z. Misiolek

Department of Materials Science and Engineering, Lehigh

University, Bethlehem, PA 18015, USA

A. Oztekin · S. Neti

Department of Mechanical Engineering and Mechanics, Lehigh

University, Bethlehem, PA 18015, USA
Keywords Ni-Zn intermediate phases · Phase identification and characterization $\cdot$ EBSD

\section{Introduction}

Solar energy, one of the most attractive renewable energy sources, is being considered as a base load power supply because of its seemingly limitless abundance. Similar to many renewable energy sources, solar energy is intermittent in nature and does not match the load patterns for energy consumption. Thus, more efficient and higher capacity storage of solar energy is an essential part of any strategies to make it competitive as a base load power supply, and the current effort is directed toward the development of methods and materials for its more efficient storage. Without such explicit storage, many solar energy plants, specifically concentrated solar power plants, cannot store or supply energy for more than seven and a half hours after energy collection has ended [1]. The use of low melting temperature salts as phase change materials (PCMs) to store thermal energy as sensible heat in current solar power plants is limiting the operating temperatures, thereby limiting the capacity and efficiency of the solar thermal energy storage (TES) systems.

In an effort to increase the storage duration, storage capacity, and overall efficiency of solar TES systems, materials that can store thermal energy using the latent heat of phase change and operate within a $400-500{ }^{\circ} \mathrm{C}$ temperature range are being considered. Materials with higher melting temperatures will enable solar TES systems to store energy at higher temperatures, which can then generate higher enthalpy steam for more efficient Rankine cycle performance [2]. Some metals are being considered as encapsulated PCMs (EPCMs) because of their 
comparable energy storage capability and higher storage temperatures with respect to salts. Not only are some metals more stable above their melting points, but they also do not suffer from dissociation of their constituents as some salts do at elevated temperatures or corrode their encapsulating materials. Lauf and Hamby [3] have shown results for the use of gallium as a PCM encapsulated in graphite canisters at elevated temperatures around $927{ }^{\circ} \mathrm{C}$. They also reported results on $\mathrm{LiF}-20 \% \mathrm{CaF}$ contained in Haynes 188 canisters at $767^{\circ} \mathrm{C}$. These systems, however, were intended for gas turbine systems operating on Brayton cycles, but show that the EPCMs' ability to operate at high temperatures exists. Recently, Zn with a melting temperature of $420{ }^{\circ} \mathrm{C}$ has been proposed as a phase change storage medium encapsulated in Ni. An analysis of the application of $\mathrm{Ni}$ as an encapsulation material for $\mathrm{Zn}$ as a phase change medium is discussed in more detail by Blaney et al. [4]. Their study established that the system could safely withstand internal stresses caused by volume and gas expansion at $450{ }^{\circ} \mathrm{C}$ and also operate at even higher temperatures. Preliminary results, however, obtained from drop calorimetry tests performed on lab-scale specimen by Zhao et al. [2] showed that the efficiency and amount of pure $\mathrm{Zn}$ available to store energy decreased with increasing numbers of melting/solidification cycles. It was found that interaction at the interface between molten $\mathrm{Zn}$ and the solid encapsulation material produced intermediate phases, which consumed the $\mathrm{Zn}$. The formation of these intermediate phases was reported to have hindered the storage performance of the system and has led to an investigation characterizing the intermediate phases formed between $\mathrm{Ni}$ and $\mathrm{Zn}$ at or around $450{ }^{\circ} \mathrm{C}$ for various high temperature exposure times.

In the $\mathrm{Ni}-\mathrm{Zn}$ binary system, there exist two parent phase regimes, $\mathrm{Ni}$ and $\mathrm{Zn}$, as well as four intermediate phase homogeneity regions, $\beta_{1}, \beta, \gamma$, and $\delta$, which are seen in the $\mathrm{Ni}-\mathrm{Zn}$ binary equilibrium phase diagram proposed by Nash and Pan [5] (Fig. 1). These intermediate phases are of importance to the $\mathrm{Ni} / \mathrm{Zn}$ encapsulation/PCM material system, because the formation and growth of one or more of these phases is detrimental to the storage ability of the TES system. Prior knowledge of the structure and compounds associated with the $\mathrm{Ni}-\mathrm{Zn}$ intermediate phases will aid in identifying those phases which formed between $\mathrm{Ni}$ and molten Zn upon solidification.

The Ni phase regime has a FCC crystal structure and has a high solubility for $\mathrm{Zn} \mathrm{[5].} \mathrm{Tamaru} \mathrm{[6]} \mathrm{confirmed} \mathrm{this} \mathrm{and}$ determined that the magnetic transition in the $\mathrm{Ni}$ phase regime decreases as $\mathrm{Zn}$ content increases. The $\mathrm{Zn}$ phase regime, having a HCP crystal structure has been found to have negligible solubility for $\mathrm{Ni}$ [5]. The $\beta_{1}$ phase has a crystal structure corresponding to a $\mathrm{CuAu}$-type $[7,8]$ structure with $P 4 / \mathrm{mmm}$ symmetry [5]. Liang et al. [9] proposed that the $\beta_{1}$ phase existed as an FCC superlattice structure. Heike et al. [7] determined a stoichiometric formula for the $\beta_{1}$ phase to be $\mathrm{NiZn}$, which was also determined by Hansen and Anderko [10]. This phase has also been modeled as a structure with substitutional defects and vacancies on two sublattices $[11,12]$. Unlike the $\beta_{1}$, the $\beta$ phase is a high temperature phase that cannot be retained upon quenching. Its crystal structure is that of the CsCl-type as reported by Heike et al. [13]. This phase has limited coverage in the literature on characterizing its crystal structure because of difficulties of retaining it at room temperature. However, Liang et al. [14] observed the transformation of the $\beta$ phase to the face centered tetragonal AuCu-type, $\beta 1$ phase.

Not necessarily agreed upon among studies of the $\gamma$ phase, the crystal structure associated with the $\gamma$ phase is the $\mathrm{Cu}_{5} \mathrm{Zn}_{8}$-type ( $\gamma$ brass) structure, which was determined by Ekman [15] who also determined the stoichiometric formula to be $\mathrm{Ni}_{5} \mathrm{Zn}_{21}$. Heike et al. [7] and Nover and Schubert [16] found that the $\gamma$ phase had a structure that correlated with the formula, $\mathrm{NiZn}_{3}$, which is at the composition where congruent melting of this phase takes place. Johansson et al. [17]. reported the stoichiometry for the $\gamma$ phase as $\mathrm{Ni}_{4} \mathrm{Zn}_{22}$. Schramm [18] reported an extension of the $\gamma$ phase, $\gamma 1$, from 73.5 to 78 at. $\% \mathrm{Zn}$ that had a distorted $\gamma$ brass structure. Morton [19] then reported that there was very little difference in the diffraction patterns of the $\gamma 1$ phase and the $\gamma$ phase, which led to the suggestion that the $\gamma 1$ phase and the $\gamma$ phase be combined into one single $\gamma$ phase region.

The $\delta$ phase crystal structure is that of a $\mathrm{CoZn}_{13}$-type structure with $C 2 / m$ symmetry as found by Critchley and Denton [20]. Owing to its narrow homogeneity range, validated by Schramm [18], the $\delta$ phase is commonly considered a stoichiometric, intermetallic, line compound, $\mathrm{NiZn}_{8}[7,10$, $11,21]$. However, Su et al. [12] considered the $\delta$ phase a stoichiometric intermetallic compound with a fixed composition of $\mathrm{Ni}_{2} \mathrm{Zn}_{15}$. Tamaru and Osawa [22] and Duchenko and Dybkov [23] also reported that the $\delta$ phase was a stoichiometric compound, but with the formula, $\mathrm{Ni}_{3} \mathrm{Zn}_{22}$.

The focus of this research is to characterize the intermediate phases formed between molten $\mathrm{Zn}$ and solid $\mathrm{Ni}$ during various durations of exposure and to determine the identity of each of the phases present. This research is motivated by the need to find storage alternatives for renewable energy sources as well as enhance existing energy sources to improve upon the cost and capacity of storage systems. Studies conducted by Lauf and Hamby [3] and Zhao et al. [2] have already shown that there is potential in using metal PCMs; however, it has also been reported that the efficiency and storage capabilities decrease because of unwanted metallic interaction between $\mathrm{Ni}$ and $\mathrm{Zn}$ during storage cycles. Describing the metallic interaction between $\mathrm{Ni}$ and $\mathrm{Zn}$ and characterizing its 
Fig. 1 Ni-Zn binary equilibrium phase diagram [5]

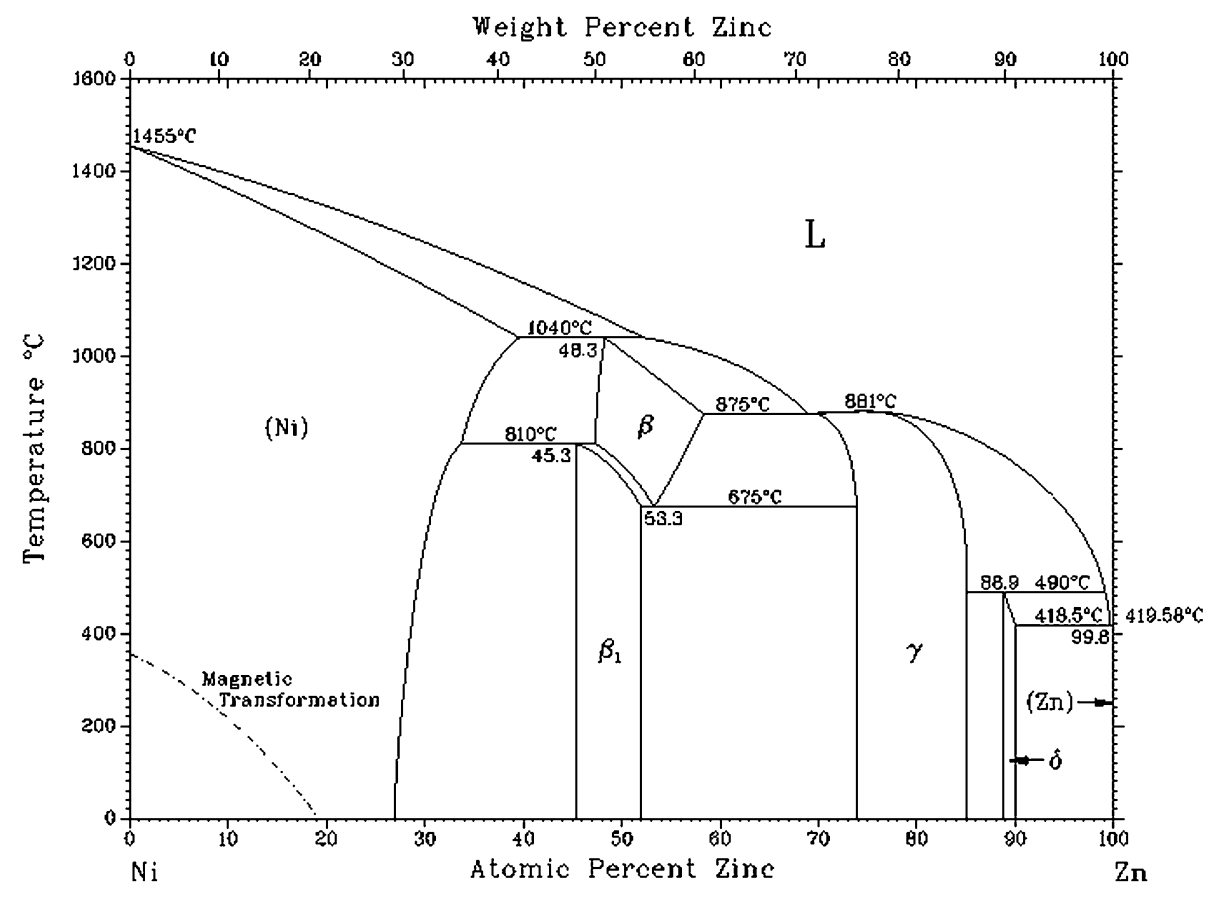

Table 1 Composition of commercially pure Ni Alloy 200 (values are reported in wt.\%)

\begin{tabular}{llllllll}
\hline Element & $\mathrm{C}$ & $\mathrm{Cu}$ & $\mathrm{Fe}$ & $\mathrm{Mn}$ & $\mathrm{Ni}$ & $\mathrm{Si}$ & $\mathrm{S}$ \\
\hline Concentration & $<0.020$ & $<0.25$ & $<0.40$ & $<0.35$ & $>99.0$ & $<0.35$ & $<0.010$ \\
\hline
\end{tabular}

Table 2 Composition of $99.997 \%$ pure $\mathrm{Zn}$ (values are reported in wt.\%)

\begin{tabular}{lllllllll}
\hline Element & $\mathrm{Al}$ & $\mathrm{Cd}$ & $\mathrm{Cu}$ & $\mathrm{Fe}$ & $\mathrm{Pb}$ & $\mathrm{Sn}$ & $\mathrm{Zn}$ & $\mathrm{OT}$ \\
\hline Concentration & $<0.002$ & $<0.003$ & $<0.002$ & $<0.003$ & 0.003 & $<0.001$ & 99.997 & $<0.010$ \\
\hline
\end{tabular}

products to support the decrease in storage capability in the $\mathrm{Zn}-\mathrm{Ni}$ EPCM system form the scope of this research.

\section{Materials and Experimental Procedure}

\section{Specimen and Testing}

The materials used in this investigation were Ni Alloy 200 (commercially pure Ni) and $99.997 \%$ pure Zn (UNS-Z13001 Zn-2 special high grade Zn). The chemical compositions of each are given in Tables 1 and 2, respectively. The Ni was supplied as $12.7-\mathrm{mm}$ (0.5 in.)-diameter rods, and the $\mathrm{Zn}$ was supplied as $36 \mathrm{~kg}$ (80 lbs.) ingots.

Five 41.2-mm-long (1.63 in.) rods were sectioned from the original Ni rods. A 4-mm (0.17 in.)-diameter hole was then drilled perpendicular to the long axis $11.1 \mathrm{~mm}$ (0.44 in.) from one end, through which a 316 stainless steel rod was placed during hot dipping in molten $\mathrm{Zn}$. The purpose of the rods was to span the inner diameter of the crucibles to suspend the Ni rods in the molten $\mathrm{Zn}$. The surfaces of each rod were then ground in succession with 320, 400, and 600 grit $\mathrm{SiC}$ papers to make the surfaces uniform and remove imperfections. Small, cylindrical billets with dimensions of 24.6-mm (0.97 in.) diameter and 25.4-mm (1 in.) height were machined from the $\mathrm{Zn}$ ingot. The rods and billets were cleaned with a degreasing agent in an ultrasonic cleaner. They were then rinsed with water and ethanol. Custom crucibles were made from an alumina silicate ceramic (lava stone), and they were baked out at $250{ }^{\circ} \mathrm{C}$ to remove any moisture before the addition of the $\mathrm{Ni}-\mathrm{Zn}$ specimen.

Single $\mathrm{Zn}$ billets were placed in each of the five crucibles, then heated to $450{ }^{\circ} \mathrm{C}$, and held there for approximately $2 \mathrm{~h}$ using a box furnace. Argon gas was flowed into the furnace at a rate of approximately $250-300 \mathrm{~mL} / \mathrm{min}$ to ensure minimal oxidation of the melt. Once the $\mathrm{Zn}$ was completely molten, one $\mathrm{Ni}$ rod was dipped into each crucible of molten $\mathrm{Zn}$. Each $\mathrm{Ni} / \mathrm{Zn}$ couple was held at $450{ }^{\circ} \mathrm{C}$ 


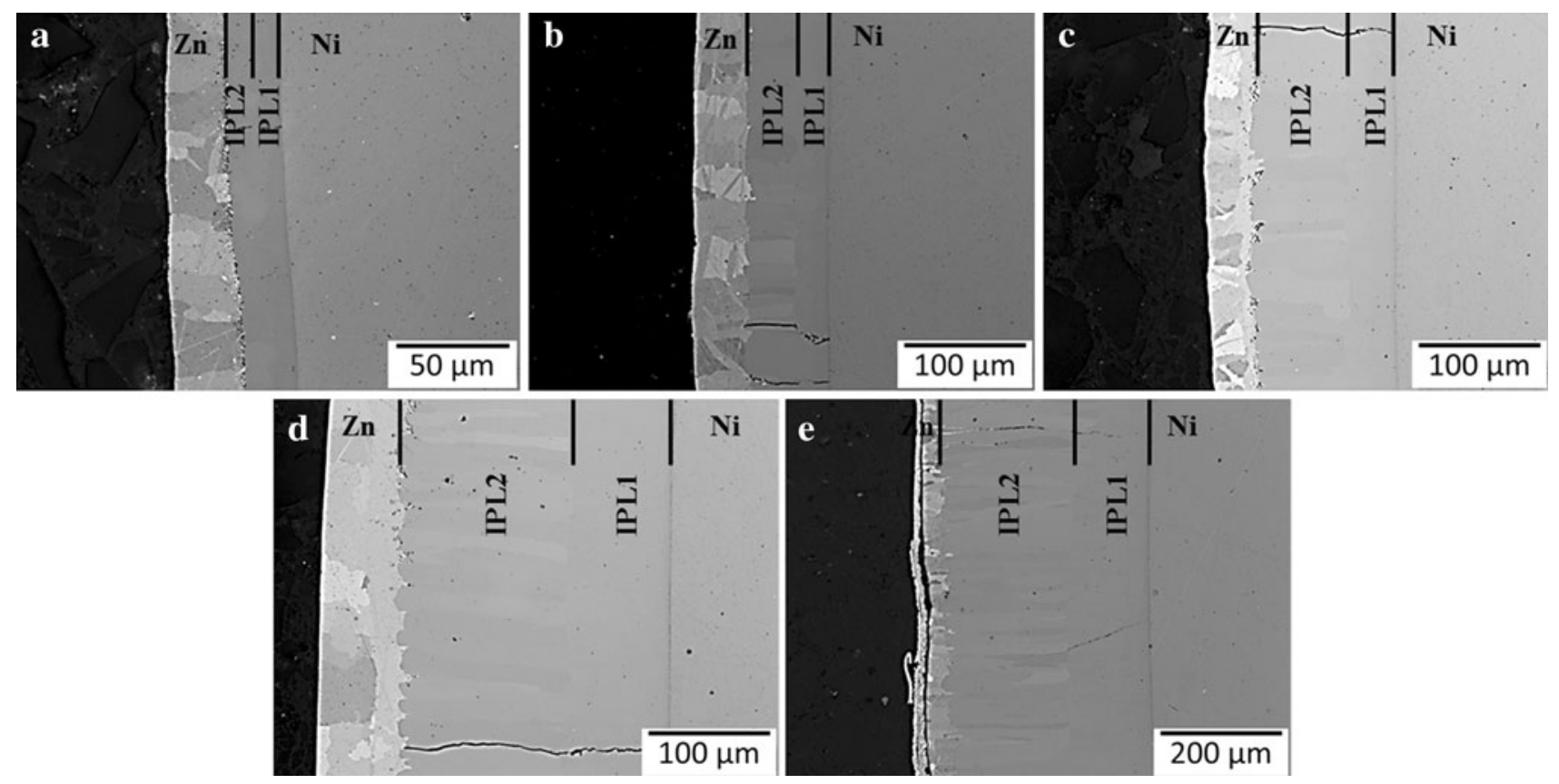

Fig. 2 Light micrographs of (a) NZ1, (b) NZ2, (c) NZ4, (d) NZ8, and (e) NZ16 samples under crossed polarized light

for various amounts of time. The hold times were 1, 2, 4, 8, and $16 \mathrm{~h}$. After the hold times were completed, the Ni rods were removed from the molten $\mathrm{Zn}$ and immediately quenched in water. Water quenching was performed to retain the microstructure and phases found at the elevated temperatures. The specimens were designated NZ1, NZ2, NZ4, NZ8, and NZ16 according to their exposure times.

\section{Metallographic Preparation}

Disk-shaped specimens were sectioned from each rod, and $2 \mathrm{~mm} \times 2 \mathrm{~mm} \times 7 \mathrm{~mm}$ specimen containing the intermediate phases were then sectioned from each disk. The specimens were mounted and metallographically prepared down to a $0.25-\mu \mathrm{m}$ diamond finish using a completely waterless process. The grinding lubricant used in place of water was a 60/40 mixture of ethyl alcohol to ethylene glycol, which had an adjusted $\mathrm{pH}$ of approximately $7-8$. The $\mathrm{pH}$ was adjusted with the addition of dissolved sodium hydroxide in ethanol. Standard waterless lubricants and suspensions were used for polishing. This inhibited galvanic corrosion of the $\mathrm{Zn}$ and Zn-containing phases in contact with $\mathrm{Ni}$. Rinsing and cleaning between each successive grinding and polishing step was also performed without the use of water.

\section{Optical Analysis}

Intermediate phases, which formed between the molten $\mathrm{Zn}$ and solid $\mathrm{Ni}$, were examined using light microscopy. Polarized light was used to increase grain contrast and differentiate the intermediate phases present in each specimen. Thickness measurements were made for each intermediate phase present as well as total layer thickness measurements for each specimen.

\section{Electron Probe Microanalysis (EPMA)}

An electron microprobe was used to determine the concentration of $\mathrm{Ni}$ and $\mathrm{Zn}$ within the intermediate phases that formed between the solid Ni Alloy 200 exposed to molten $99.997 \%$ pure $\mathrm{Zn}$. The electron micoprobe was operated with an accelerating voltage of $20 \mathrm{kV}$, a beam current of $30 \mathrm{nA}$, a $5-\mu \mathrm{m}$ probe diameter, and at an analysis magnification of $\times 4000$. Concentration profiles from the $\mathrm{Ni}$, across the intermediate phases, to the $\mathrm{Zn}$ were measured for each of the five samples.

\section{Electron Backscatter Diffraction (EBSD) Analysis}

EBSD was performed on each of the five specimens. Five to ten patterns were acquired and indexed within each intermediate phase region of each of the five specimens to provide statistical confirmation that the indexed phases were correctly indexed. The patterns and indexes were recorded for each layer from each sample.

\section{Results and Discussion}

It was observed that only two out of four possible intermediate phases indicated in the equilibrium phase diagram in Fig. 1 were present in each specimen. This is in contrast 
to the model of the Ni-Zn system under similar conditions proposed by Alzahrani [24], in which all four intermediate phases $\left(\alpha(\mathrm{Ni}), \beta_{1}, \gamma\right.$, and $\delta$ ) were predicted to be present. Figure 2 shows representative light micrographs of each of the five specimens. These intermediate phase layers (IPL1, adjacent to $\mathrm{Ni}$; IPL2, adjacent to $\mathrm{Zn}$ ) were distinguishable because of different grain morphologies color, which was enhanced with polarized light. In order to identify the intermediate phase layers, EPMA and EBSD were used as characterization techniques.

Using EPMA, concentration profiles were made from regions of pure $\mathrm{Ni}$, across both intermediate phase layers, to regions of pure Zn in NZ1, NZ2, NZ4, NZ8, and NZ16. Figure 3 shows the concentration profiles obtained from EPMA. The average composition ranges measured across IPL1 and IPL2 for each specimen were found to be approximately 78.5-85.4 and 87.6-90.1 wt.\% Zn, respectively. The individual composition ranges for each layer and specimen are shown in Table 3 along with the layer thicknesses over which the compositions were measured. These composition ranges lie within the $\gamma$ and $\delta$ phase homogeneity regions of the $\mathrm{Ni}-\mathrm{Zn}$ equilibrium phase diagram shown in Fig. 1, which exist from 76.0 to 87.0 wt.\% $\mathrm{Zn}$ and 89.5 to $91.0 \mathrm{wt} . \% \mathrm{Zn}$, respectively. It should be noted that the average composition range determined for IPL2 extends slightly beyond the Ni-rich side of the $\delta$ phase into the $\gamma+\delta$ phase regime.

Further confirmation of the identification of the intermediate phase layers was established with EBSD. Figure 4 shows representative EBSD patterns for pure $\mathrm{Ni}$, the first and second intermediate phase layers, and pure $\mathrm{Zn}$. Alongside each pattern is the same pattern with a simulated and indexed pattern overlay. The first intermediate phase layer, adjacent to the $\mathrm{Ni}$, was indexed as $\mathrm{NiZn}_{3}$, which agrees with the compound formula and structure ascribed to the $\gamma$ phase by Heike et al. [7]. and Nover and Schubert [16]. The second intermediate phase layer, adjacent to the $\mathrm{Zn}$, was indexed as $\mathrm{Ni}_{3} \mathrm{Zn}_{22}$, which agrees with the compound formula and structure ascribed to the $\delta$ phase by Tamaru and Osawa [22] and Duchenko and Dybkov [23]. These two compounds have crystal structures of the gamma brass and monoclinic $\mathrm{CoZn}_{13}$-type structures, respectively. The gamma brass, orthorhombic structure as indexed by the EBSD software for $\mathrm{NiZn}_{3}$ had the following associated lattice parameters and lattice vector angles: $a=33.326 \AA, b=8.869 \AA, c=12.499 \AA$, and $\alpha=\beta=$ $\gamma=90^{\circ}$. Likewise, the lattice parameters and lattice vector angles associated with the monoclinic $\mathrm{Ni}_{3} \mathrm{Zn}_{22}$ phase were the following: $a=13.370 \AA, b=7.47 \AA, c=7.65 \AA$, and $\alpha=\gamma=90^{\circ}$ and $\beta=113.3^{\circ}$. These values and structures were determined by Nover and Schubert [16] and Critchley and Denton [20] for the $\gamma$ and $\delta$ phases, respectively, and were found to be appropriate fits for IPL1 and IPL2.
In all cases, the diffraction patterns obtained for IPL2 were not well defined and obscured because of what looked like multiple patterns existing simultaneously. This caused the patterns to occasionally be identified by the indexing software as $\mathrm{Ni}_{5} \mathrm{Zn}_{21}, \mathrm{NiZn}_{7.33}$, and $\mathrm{NiZn}_{3}$. A plausible explanation for the indexing of multiple phases is that the composition range associated with the second intermediate phase layer extends into the $\gamma+\delta$ phase regime (IPL2: 87.6-90.1 wt.\% Zn; $\gamma+\delta: \quad 87.0-89.5$ wt.\% $\mathrm{Zn} ; \quad \delta$ : 89.5-91.0 wt.\% Zn). This slight extension into the $\gamma+\delta$ phase regime may cause the presence of two crystal structures to simultaneously exist in IPL2, which would in turn distort the EBSD patterns and make discerning a unique, indexed pattern difficult. However, all of the possible crystal structures identified by the software $\left(\mathrm{Ni}_{5} \mathrm{Zn}_{21}\right.$, $\mathrm{NiZn} \mathrm{n}_{7.33}$, and $\mathrm{NiZn}$ ) for IPL2 have all been assigned to the $\gamma$ and $\delta$ phases in the literature.

The composition ranges of IPL1 and IPL2 $(\gamma$ and $\delta)$ in each specimen exist over thicknesses, which are proportional to their exposure times at $450{ }^{\circ} \mathrm{C}$. Figure 5 shows the relation between layer thickness and exposure time. As the exposure time increases, the layer thicknesses of IPL1 and IPL2, as well as the total combined layer thickness increase; however, the thicknesses of IPL1 and IPL2 consistently differed from each other. The thinnest total combined layer was of $25-\mu \mathrm{m}$ thickness, with IPL1 and IPL2 having respective thicknesses of 11 and $14 \mu \mathrm{m}$ found in NZ1. The thickest total combined layer, found in NZ16 was of $335-\mu \mathrm{m}$ thickness, with IPL1 and IPL2 being of 134- and 201- $\mu \mathrm{m}$ thicknesses, respectively. Table 3 summarizes the thicknesses as well as composition ranges measured for IPL1 and IPL2 in each specimen.

The IPL2 layer was found to be consistently thicker than the IPL1 layer in each specimen. This is due to the different diffusivities in each phase as well as a difference in crystal structures of $\gamma$ and $\delta$, which have a gamma brass structure and monoclinic CoZn $\mathrm{n}_{13}$-type structure, respectively. According to Duchenko [25], the reaction diffusion constant for the $\gamma$ and $\delta$ phases can be described by the Arrhenius equation:

$k_{1}=A \exp (-E / R T)$

where $k_{1}$ is the reaction diffusion constant $\left(\mathrm{m}^{2} / \mathrm{s}\right), A$ is the pre exponential $\left(\mathrm{m}^{2} / \mathrm{s}\right), E$ is the activation energy $(\mathrm{J}), R$ is the ideal gas constant $(\mathrm{J} / \mathrm{mol} \mathrm{K})$, and $T$ is temperature $(\mathrm{K})$. The values of $A$ and $E$ for $\gamma$ and $\delta$ were determined by Duchenko to be $1.1 \times 10^{-9} \mathrm{~m}^{2} / \mathrm{s}$ and $55.4 \mathrm{~kJ}$ and $6.4 \times 10^{-6} \mathrm{~m}^{2} / \mathrm{s}$ and $103.3 \mathrm{~kJ}$, respectively. Using the values found by Duchenko and the Arrhenius relation with $T=723 \mathrm{~K}\left(450{ }^{\circ} \mathrm{C}\right)$, values of $k_{1}$ (diffusivity) for each phase were found. The diffusivities for the $\gamma$ and $\delta$ phases were $1.09 \times 10^{-13}$ and $2.20 \times 10^{-13} \mathrm{~m}^{2} / \mathrm{s}$, respectively. The diffusivity in the $\delta$ phase is approximately two times faster than that in the $\gamma$ phase. This could account for the formation of thicker 

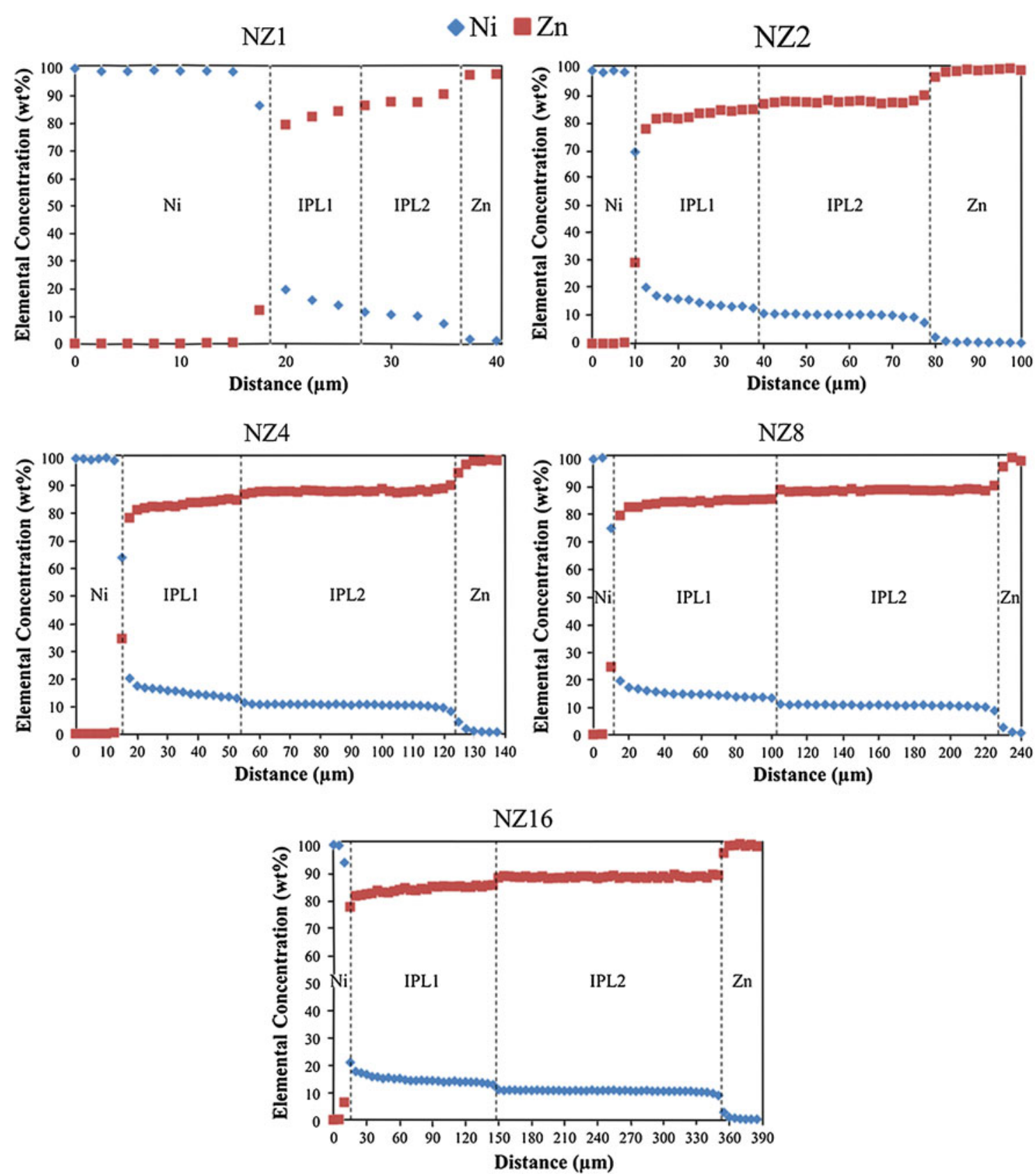

Fig. 3 Linear concentration profiles for NZ1, NZ2, NZ4, NZ8, and NZ16 samples determined by EPMA. The average composition ranges of the IPL1 and IPL2 layers are approximately 78.5-85.4 and 87.6-90.1 wt.\% Zn, respectively

Table 3 Composition ranges and layer thicknesses for IPL1 and IPL2 determined for each specimen using EPMA

\begin{tabular}{|c|c|c|c|c|c|}
\hline Specimen & NZ1 & NZ2 & NZ4 & NZ8 & NZ16 \\
\hline \multicolumn{6}{|l|}{ IPL1 } \\
\hline Composition range (wt.\% Zn) & $79.5-86.5$ & $77.9-85.0$ & $78.1-84.6$ & $79.6-85.4$ & $77.9-85.8$ \\
\hline Thickness $(\mu \mathrm{m})$ & 11 & 27 & 44 & 85 & 134 \\
\hline \multicolumn{6}{|l|}{ IPL2 } \\
\hline Composition range (wt.\% Zn) & $87.8-90.5$ & $87.0-90.2$ & $86.8-90.0$ & $88.9-90.4$ & $88.5-89.5$ \\
\hline Thickness $(\mu \mathrm{m})$ & 14 & 40 & 72 & 136 & 201 \\
\hline
\end{tabular}



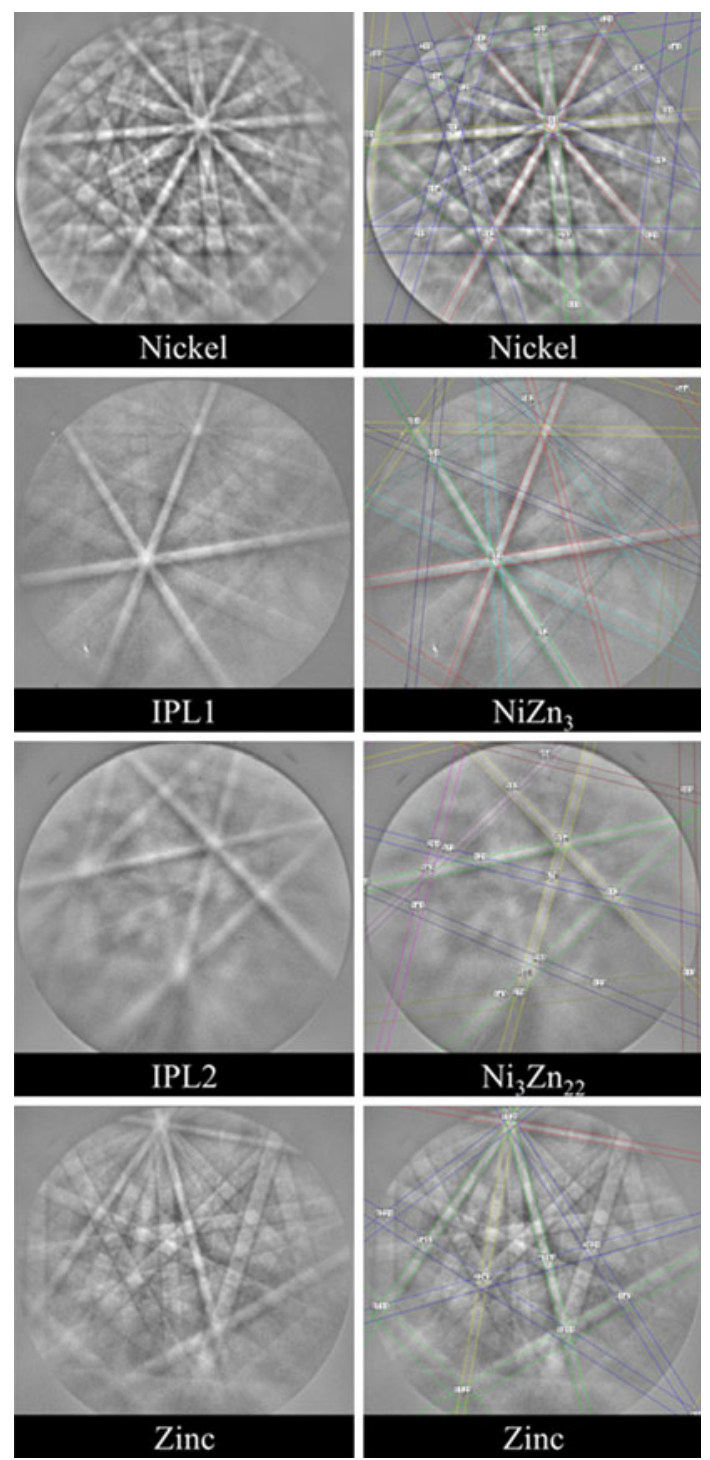

Fig. 4 EBSD patterns for Ni, IPL1, IPL2, and Zn with corresponding simulated pattern overlays alongside on the right of each pattern

layers of $\delta$ phase, because atoms can move quickly through the volume of the IPL2 layer and to the interface to promote growth of the IPL2 layer. Another possible reason for the thicker layers of IPL2 is that these layers are adjacent to molten $\mathrm{Zn}$. The $\mathrm{Zn}$ atoms in the molten state are highly mobile and will be able to diffuse into the IPL2 layer, in effect directly supplying $\mathrm{Zn}$ atoms to form $\mathrm{Ni}_{3} \mathrm{Zn}_{22}$. In comparison, to form the IPL1 layer ( $\gamma$ phase) the $\mathrm{Zn}$ atoms have a longer path to travel to form $\mathrm{NiZn}_{3}$, because they must first diffuse through the IPL2 layer.

A typical power law expression in the form of

$x=k t^{n}$

where $x$ is the thickness, $k$ is the growth rate constant, $t$ is time, and $n$ is the growth exponent set equal to 0.5 (indicating

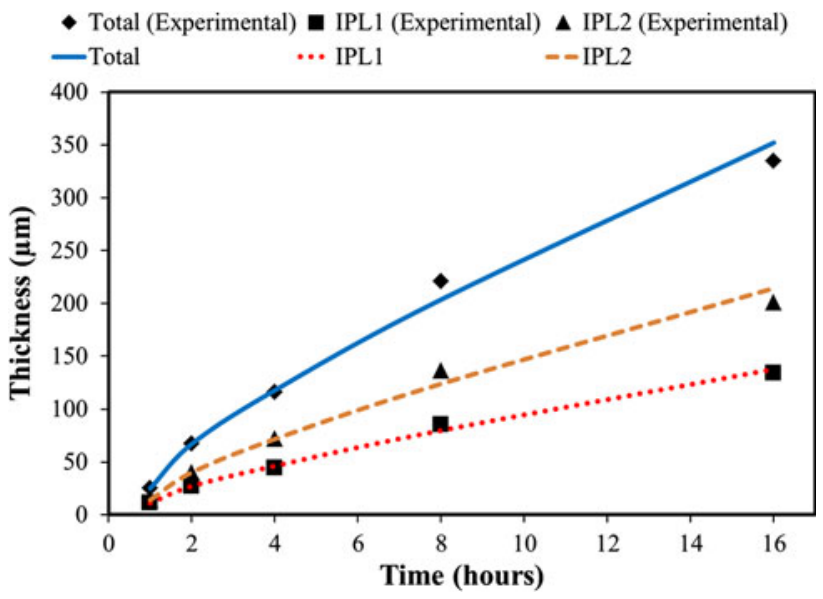

Fig. 5 Experimentally measured thicknesses and thickness trend lines with respect to exposure time for IPL1, IPL2, and the combined (total) layers

diffusion controlled layer growth), was found to not fit the experimental data well. A growth exponent equal to 0.5 is typical for solid/solid metallic interaction and has been reported to fit well to layer formation in binary systems by others [23, 26-28]. Duchenko and Dybkov [23], who have performed much research on the $\mathrm{Ni}-\mathrm{Zn}$ system, reported that a parabolic relationship $(n=0.5)$ between the layer thickness and isothermal hold times shows strong correlation with experimental data for the $\mathrm{Ni}-\mathrm{Zn}$ system at elevated temperatures below the melting temperature of $\mathrm{Zn}\left(420^{\circ} \mathrm{C}\right)$. In the current experiment, a parabolic correlation could not be used, because of kinetics associated with solid/liquid interactions. The presence of a liquid component at an elevated temperature causes diffusion to occur at rates, which are higher than rates associated with solid/solid diffusion, as well as introduces exacerbated reaction-diffusion kinetics because of dissolution of the solid component into the liquid [29].

Even though a simple parabolic power law curve did not fit the experimental data, the data did show typical trends for layer formation. The data presented in Fig. 5 still show common trends for experimentally measured layer thicknesses in relation to exposure time. As the exposure time increased, the thickness of the layers increased, but at a decreasing rate. The decreasing growth rate may be associated with increased layer thickness. As the layer thickness increases, the diffusion path for $\mathrm{Ni}$ and $\mathrm{Zn}$ atoms to the layer interfaces also increases, in effect decreasing the contribution to growth from atomic diffusion. $\mathrm{Ni}$ and $\mathrm{Zn}$ atoms cannot be supplied to the interfaces so quickly, and further growth will be limited by diffusion.

In each case, only two intermediate phases were observed, and their presence was confirmed with EPMA and EBSD techniques. The formation of fewer phases than predicted by equilibrium phase diagrams has been reported for many other binary and multicomponent metallic systems such as 
the $\mathrm{Fe}-\mathrm{Al}$ system [30], the $\mathrm{Cu}-\mathrm{Zn}$ system [31], and the $\mathrm{Fe}-\mathrm{Zn}$ system [32]. For the $\mathrm{Ni}-\mathrm{Zn}$ system, in particular, it has been proposed that formation of only two phases occurs because of chemical reactions at the interface between $\mathrm{Ni}$ and $\mathrm{Zn}$ and at the interfaces between intermediate phases. Dybkov [29] suggests that $\mathrm{Ni}_{3} \mathrm{Zn}_{22}$ ( $\delta$ phase) immediately forms, and after its thickness becomes significant to the point where appreciable diffusion of $\mathrm{Zn}$ through the layer occurs, $\mathrm{NiZn}_{3}(\gamma$ phase) begins to form. Once the two phases are present, they grow simultaneously according to chemical reactions expressed by Dybkov [29], but at unequal rates because of the diffusivity through each phase and the relative mobility of atoms from the parent materials ( $\mathrm{Ni}$ and $\mathrm{Zn}$ ).

\section{Conclusions}

In this study, solid Ni rods were dipped into molten $\mathrm{Zn}$ at $450{ }^{\circ} \mathrm{C}$ for exposure times of $1,2,4,8$, and $16 \mathrm{~h}$. The subsequent intermediate phases, which formed between the $\mathrm{Ni}$ and $\mathrm{Zn}$, were analyzed, and it was found that in each specimen only two intermediate phase layers formed under the experimental conditions. The average concentration ranges over the two respective thicknesses were 78.5-85.4 and 87.6-90.1 wt.\% Zn. These concentration ranges correspond to the $\gamma$ and $\delta$ phase homogeneity regions of the $\mathrm{Ni}-\mathrm{Zn}$ equilibrium phase diagram, respectively. Further confirmation of the presence of the $\gamma$ and $\delta$ phases was provided by EBSD, which resulted in the identification of $\mathrm{NiZn}_{3}$ and $\mathrm{Ni}_{3} \mathrm{Zn}_{22}$. These two compounds have been ascribed to the formation of the $\gamma$ and $\delta$ phases, respectively, by other authors. Results also showed that as the exposure time increased, the total layer thickness increased at a decreasing rate, which indicated that the layer growth rate decreased because of longer diffusion paths due to increasing thicknesses.

Acknowledgments The authors gratefully acknowledge the support for this research from the U.S. Department of Energy under Contract Number DE-FG36-08GO18050. Partial support for Wojciech Z. Misiolek is provided by the Loewy Family Foundation through the Loewy Professorship at Lehigh University.

\section{References}

1. T. Ruekert, R. Diver, G. Kolb, H. Price, Solar thermal renewable energy technology characterizations, Topical Report, TR-109496, EERE and EPRI (1997)

2. W. Zhao, Y. Zheng, J.C. Sabol, A. Oztekin, S. Neti, K. Tuzla, W.Z. Misiolek, J.C. Chen, Thermal energy storage using zinc as encapsulated phase change material, in Proceedings of the ASME 2011 International Mechanical Engineering Congress \& Exposition, IMECE2011-63988, Nov 11-12, 2011, Denver, CO, pp. 1-8 (2011)
3. R.J. Lauf, C. Hamby Jr., Metallic Phase-Change Materials for Solar Dynamic Energy Storage Systems (Oak Ridge National Laboratory, Oak Ridge, 1990), ORNL/TM-11351, pp. 1-35

4. J.J. Blaney, S. Neti, W.Z. Misiolek, A. Oztekin, Containment capsule stresses for encapsulated phase change materials. Appl. Therm. Eng. (in press) (2012)

5. P. Nash, Y.Y. Pan, The Ni-Zn (nickel-zinc) system. J. Phase Equilib.: Bull. Alloy Phase Diagr. 8(5), 422-430 (1987)

6. K. Tamaru, On the equilibrium diagram of the nickel-zinc system. Sci. Rep. Tohoku Imp. Univ. 21, 344-346 (1932)

7. W. Heike, J. Schramm, O. Vaupel, Die Gefuegeaufbau der Nickel-Zinc Legierung, Metallwirtschaft, Metallwissenschaft. Metalltechnik 11(39), 525-530 (1932)

8. V. Caglioti, X-ray investigations on zinc-nickel alloys. Atti. Congr. Nazl. Chim. Para. Appl. 4 (1933); abstract in Chem. Zentr. 105(1), 1283 (1934) (in German), 431-441

9. W.W. Liang, Y.A. Chang, S. Lau, The effect of lattice disorder on the thermodynamic properties of the fct $\beta 1-\mathrm{Ni}-\mathrm{Zn}$ alloys. Acta Metall. Mater. 21, 629-637 (1973)

10. M. Hansen, K. Anderko, Constitution of Binary Alloys (McGrawHill, Maple Press Co., York, 1958), pp. 1059-1062

11. G.P. Vassilev, T. Gomez-Acebo, J. Tedenac, Thermodynamic optimization of the $\mathrm{Ni}-\mathrm{Zn}$ system. J. Phase Equilib. 21(3), 287-301 (2000)

12. X. Su, N. Tang, J.M. Toguri, Thermodynamic assessment of the Ni-Zn system. J. Phase Equilib. 23(2), 140-148 (2002)

13. W. Heike, J. Schramm, O. Vaupel, Zu dem System Nickel-Zink. Metallwirtschaft 15, 655-662 (1936) (in German)

14. W.W. Liang, J.W. Franks, Y.A. Chang, Thermodynamic activity of the $\beta^{\prime}-\mathrm{NiZn}$ phase by the dew-point method. Metall. Trans. 3, 2555-2556 (1972)

15. W. Ekman, Structure analysis of the binary alloys of transition elements with Zn, Cd and Al. Z. Phys. Chem. B 12, 57-77 (1931) (in German)

16. G. Nover, K. Schubert, The crystal structure of NiZn2.r. J. LessCommon Met. 75, 51-63 (1980)

17. A. Johansson, H. Ljung, S. Westman, X-ray and neutron diffraction studies on $\Gamma-\mathrm{Ni}, \mathrm{Zn}$ and $\Gamma-\mathrm{Fe}, \mathrm{Zn}$. Acta Chem. Scand. 22, 2743-2753 (1968)

18. J. Schramm, X-ray investigation of phases and phase limits of the Zn alloy systems with Fe, Co and Ni. Z. Metallkd. 30, 122-130 (1938) (in German)

19. A.J. Morton, The $\gamma$-phase regions of the copper-zinc, nickel-zinc and palladium-zinc binary systems. Acta Metall. Mater. 27(5), 863-867 (1979)

20. J.K. Critchley, S. Denton, Crystal structure of $\delta$-NiZn. J. Inst. Met. 99, 26-27 (1971)

21. G. Kong, J. Lu, Q. Xu, Interfacial reaction between solid nickel and liquid zinc. J. Wuhan Uni. Tech.-Mater Sci. Ed. 23(5), 712-716 (2008)

22. K. Tamaru, A. Osawa, On further investigation of the equilibrium diagram of the Nickel-Zinc system. Sci. Rep. Tohoku Imp. Univ. 23, 794-815 (1935)

23. O.V. Duchenko, V.I. Dybkov, Phase formation in the nickel-zinc reaction couple. Powder Metall. Met. C+ 37(11-12), 641-647 (1998)

24. B.A. Alzahrani, Diffusion model and experimental verification of interfacial multiple phase growth in a thermal energy storage binary system, M.S. Thesis, Department of Mechanical Engineering and Mechanics, Lehigh University, 2011

25. O.V. Duchenko, Diffusional formation of intermetallic layers in the nickel-zinc reaction couple. Metallofiz. Nov. Tekh. 21(2), 89-92 (1999)

26. M.S. Lee, C. Chen, C.R. Kao, Formation and absence of intermetallic compounds during solid-state reactions in the $\mathrm{Ni}-\mathrm{Bi}$ system. Chem. Mater. 11, 292-297 (1998) 
27. H. Springer, A. Kostka, E.J. Payton, D. Raabe, A. KaysserPyzalla, G. Eggeler, On the formation and growth of intermetallic phases during interdiffusion between low-carbon steel and aluminum alloys. Acta Mater. 59, 1586-1600 (2011)

28. S. Ueda, O. Taguchi, Y. Iijima, G. Takahashi, K. Yamaguchi, Growth kinetics of intermediate phase layers in an early stage of hot dip galvanizing at $450{ }^{\circ} \mathrm{C}$. J. Mater. Sci. 43, 5666-5668 (2008)

29. V.I. Dybkov, Reaction Diffusion and Solid State Chemical Kinetics (The IPMS Publications, Kyiv, 2002)
30. K. Bouche, F. Barbier, A. Coulet, Intermetallic growth between solid iron and molten aluminum. Mater. Sci. Eng. A 429, 167-175 (1998)

31. D. Li, Q. Wang, G. Li, X. Lv, K. Nakajima, J. He, Diffusion layer growth at $\mathrm{Zn} / \mathrm{Cu}$ interface under uniform and gradient high magnetic fields. Mater. Sci. Eng. A 495, 244-248 (2008)

32. C.E. Jordan, A.R. Marder, Fe-Zn phase formation in interstitial free steels hot-dip galvanized at $450{ }^{\circ}$ C. J. Mater. Sci. 32, 5593-5602 (1997) 